\title{
Dietary selenium augments sarcoplasmic calcium release and mechanical performance in mice
}

\author{
Dóra Bodnár', Olga Ruzsnavszky', Tamás Oláh', Beatrix Dienes ${ }^{1}$, Ildikó Balatoni ${ }^{1}$, Éva Ungvári², Ilona Benkő², \\ Beáta Babka ${ }^{3}$, József Prokisch ${ }^{3}$, László Csernoch ${ }^{1}$ and Péter Szentesi ${ }^{* *}$
}

\begin{abstract}
Background: As an essential trace element selenium plays a significant role in many physiological functions of the organs. It is found within muscles as selenocystein in selenoprotein $\mathrm{N}$, which is involved in redox-modulated calcium homeostasis and in protection against oxidative stress.

Methods: The effects of two different selenium compounds (selenate and NanoSe in 0.5 and 5 ppm concentration for two weeks) on muscle properties of mice were examined by measuring in vivo muscle performance, in vitro force in soleus (SOL) and extensor digitorum longus (EDL) muscles and changes in intracellular $\mathrm{Ca}^{2+}$ concentration in single fibers from flexor digitorum brevis (FDB) muscle.. Western-blot analysis on muscle lysates of EDL and SOL were used to measure the selenoprotein $\mathrm{N}$ expression. Control mice received 0.3 ppm Se.

Results: While the grip force did not change, 5 ppm selenium diets significantly increased the speed of voluntary running and the daily distance covered. Both forms of selenium increased significantly the amplitude of single twitches in EDL and SOL muscle in a concentration dependent manner. Selenate increased fatigue resistance in SOL. The amplitude of the calcium transients evoked by $\mathrm{KCl}$ depolarization increased significantly from the control of $343 \pm 44 \mathrm{nM}$ to $671 \pm 51 \mathrm{nM}$ in the presence of $0.5 \mathrm{ppm}$ selenate in FDB fibers. In parallel, the rate of calcium release during short depolarizations increased significantly from $28.4 \pm 2.2$ to $45.5 \pm 3.8$ and $52.1 \pm 1.9 \mu \mathrm{M} / \mathrm{ms}$ in the presence of $0.5 \mathrm{ppm}$ NanoSe and selenate, respectively. In $0.5 \mathrm{ppm}$ concentration both selenium compounds increased significantly the selenoprotein $\mathrm{N}$ expression only in EDL muscle.

Conclusions: Selenium supplementation augments calcium release from the sarcoplasmic reticulum thus improves skeletal muscle performance. These effects are accompanied by the increased selenoprotein $\mathrm{N}$ expression in the muscles which could result in increased oxidative stress tolerance in case of long lasting contraction.
\end{abstract}

Keywords: Selenium, Skeletal muscle, Force, Intracellular calcium concentration, Selenoprotein

\section{Background}

Significant proportion of locomotor diseases is caused by muscle weakness or wasting, but the biological mechanisms involved in these processes are not completely understood. One potential cause could be the accumulation of nuclear and mitochondrial DNA damage and increases in oxidative stress which leads to the loss of muscle fibers and, thus, decreased functionality of skeletal muscle [1]. Selenium as a

\footnotetext{
* Correspondence: szentesi.peter@med.unideb.hu

${ }^{1}$ Department of Physiology, Faculty of Medicine, University of Debrecen, P.O. Box 400, H-4002 Debrecen, Hungary

Full list of author information is available at the end of the article
}

trace element with antioxidant properties plays an important role in muscle function [2], and associated enzymes as glutathione reductase and peroxidase protect muscle fibers from reactive oxygen species [3].

Selenium is a trace mineral needed in small amounts each day. It is well known for its antioxidant properties which are responsible for its antiviral and anticancer abilities (for review see [4]), but it is also important for normal muscle function. Skeletal muscle disorders manifesting in muscle pain, fatigue, proximal weakness, and serum creatine kinase elevation have been reported in patients with selenium deficiency [5]. Recent experiments on transgenic 
mice lacking the antioxidant enzyme superoxide dismutase have shown an acceleration of sarcopenia due to neuromuscular degeneration following mitochondrial dysfunction. This finding indicates that a decline in the ability to cope with an increase in oxidative stress may be, at least in rodents, an important cause of sarcopenia [6]. In ruminant animals, selenium deficiency causes white muscle disease, the symptoms of which are muscle weakness and degeneration of cardiac and skeletal muscle [7]. Similar human myopathy has also been described [8] and severe selenium deficiency is associated with skeletal muscle problems [5].

The recommended daily dietary allowance (RDA) for selenium according to the European Union is $20-75 \mu \mathrm{g}$ for adults and 10-25 $\mu$ g for children [9]. Unfortunately, the selenium intake is below the recommended amount in Europe at present [10]. Therefore, there are extensive actions to initiate selenium supplementation in the population, however, because its toxicity in high concentration the results are diverse and sometime controversial.

The supplementation of vitamins and elements is very important and one way to do this is the application of nanoparticles. They have distinctive properties and extensive application in the healthy diet. Among the various types of nanoparticles, selenium has good absorption capacity, lower toxicity, high bioavailability and interaction with proteins [11]. In the past few years a new type of nano-selenium (NanoSe) was developed as nano sized elemental selenium particles (between 100 and $500 \mathrm{~nm}$; [12]). It has lower toxicity and better physiological effects than inorganic mineral forms of selenium. Recent studies proved that the toxicity of Se forms decreased in the following order: selenate $>$ selenite $>$ NanoSe $>$ LactoMi$\operatorname{croSel}^{\bullet}[13,14]$. NanoSe is produced by lactic acid bacteria (LactoMicroSel ${ }^{\circ}$ is the same, but made of milk producing dried yoghurt powder). While selenate is absorbed as is, NanoSe is transformed into selenite in vivo.

The biological functions of Se are associated with selenoproteins, a family of proteins which contain this micronutrient in the form of selenocysteine. The functions of several selenoproteins have been described, but most of them have no known functions. Its conservation among species and their preserved production pathway highlight the importance of these proteins. Most of those selenoproteins whose function is identified are catalytically active in redox processes. One of them is glutathione peroxidase $(\mathrm{GPx})$ which plays a role in the catalytic decomposition of $\mathrm{H}_{2} \mathrm{O}_{2}$ into $\mathrm{H}_{2} \mathrm{O}$ and oxygen. In mammals, there are several selenocysteine-containing GPx and they modify the oxidation of reduced glutathione (GSH) which is present in millimolar concentrations in muscle fibers. Nevertheless, the only selenoprotein implicated so far in a human genetic disorder associated with skeletal muscles is selenoprotein $\mathrm{N}$ (SelN), encoded by the SEPN1 gene [15] which manifests in muscle dystrophy. It was shown that SelN is involved in redox-modulated calcium homeostasis in skeletal muscle [16] so it could alter the contraction.

Shortening of muscle is a multi-step process called excitation contraction (EC) coupling. The trigger action potential traveling along the sarcolemma and the transverse-(T-) tubule membranes activates the calcium release from the intracellular store (sarcoplasmic reticulum, SR) via $\mathrm{Ca}^{2+}$ release channels (ryanodine receptor, RyR; [17]). The voltage sensor/L-type calcium channel in the Ttubular membrane (dihydropyridine receptor, DHPR; [18]) activates RyR via a direct conformational coupling. The released calcium ions bind to the regulatory sites on troponin- $C$ and initiate muscle contraction. During relaxation calcium is moved back into the SR via the sarcoplasmic calcium pump (SERCA). Since both RyR and SERCA activity are altered by oxidation, the antioxidant selenium could have an impact on EC-coupling by modifying intracellular calcium homeostasis.

The specific aim of the present project was to investigate the steps of EC coupling on selenium fed mice and to understand how its modification leads to the observed changes in muscle performance.

\section{Methods}

\section{Chemicals and selenium sources}

Chemicals, unless otherwise stated, were purchased from Sigma (St. Louis, MO, USA) and were of analytical grade.

Inorganic mineral form of selenate (sodium selenate, $\mathrm{Na}_{2} \mathrm{SeO}_{4}$ ) and selenite (sodium hydrogen selenite, $\mathrm{NaH}-$ $\mathrm{SeO}_{3}$ ) were purchased from CEDA Chemicals (Duelmen, Germany). For producing nano-sized (100 to $500 \mathrm{~nm}$ diameter) elemental selenium (NanoSe) we used the inorganic selenite dissolved in $5 \%$ MRS Broth bacteria culture media. The selenite containing media was inoculated with Lactobacillus casei probiotic yoghurt bacteria, freshly produced from freeze-dried bacteria (three times re-inoculation). The final concentration of selenium was $200 \mathrm{mg} / \mathrm{L}$. The prepared solution was fermented at $37{ }^{\circ} \mathrm{C}$ in a shaking incubator for $48 \mathrm{~h}$. After the fermentation the red color of the elemental selenium nano-sized balls produced by the bacteria can be seen (see Additional file 1: Figure S1). To extract the pure NanoSe particles we centrifuged MRS, digested the bacteria pellet with cc. hydrochloric acid, and washed as well as filtered the cell debris out. The final NanoSe is a sol (a colloidal suspension of solid particles with diameter below $500 \mathrm{~nm}$ ).

\section{Animal care}

Animal experiments conformed to the guidelines of the European Community (86/609/EEC). The experimental protocol was approved by the institutional Animal Care Committee of the University of Debrecen (4/2011/DE $\mathrm{MAB})$. The 25-week-old BDF1 male mice weighing an 
average of $27 \mathrm{~g}$ were housed in plastic cages with mesh covers, and fed with pelleted mouse chow and water ad libitum. Room illumination was an automated cycle of $12 \mathrm{~h}$ light and $12 \mathrm{~h}$ dark, and room temperature was maintained within the range $22-25^{\circ} \mathrm{C}$.

The animal model used was described previously [13]. In brief, inorganic sodium selenate and NanoSe was administered for 14 days at concentrations of 0.5 , and $5 \mathrm{ppm}$ (particle per million) Se, equivalent to 0.5 , and $5 \mathrm{mg} \mathrm{Se} / \mathrm{kg}$ food, corresponding to an estimated 4, and $40 \mu \mathrm{g} / \mathrm{kg}$ body weight/day Se uptake, respectively. The length of feeding and the applied concentrations were chosen to minimize toxicity of selenium. Forming lab diet we minced the pelleted mouse chow and mixed carefully with the appropriate amount of distillated water dissolved sodium selenate, as well as homogenized NanoSe sol. After mixing we granulated and dried the selenium containing chow again. The concentration of the NanoSe sol and selenate in the mixed chows was verified with atomic fluorescence spectrometer after nitric acid destruction. The control lab diet [19] was obtained from Charles River (Wilmington, MA, USA) and it contains sodium selenite. Its $0.3 \mathrm{ppm}$ Se content was subtracted from the administered Se doses. The control group received no additional Se besides that of the basal diet. The number of animals in the groups is presented in Table 1. Bodyweights of the animals were measured daily as well as their daily food intake.

Animals were anaesthetized and sacrificed following a protocol approved by the Animal Care Committee of the University of Debrecen. After pentobarbital anesthesia (27 $\mathrm{mg} / \mathrm{kg}$ ), the $m$. flexor digitorum brevis (FDB), the $m$. extensor digitorum longus (EDL) and $m$. soleus (SOL) from the hind limb were dissected.

\section{In vivo experiments}

Voluntary activity wheel measurement Mice from different groups of treatment were singly housed in a cage with a mouse running wheel (Campden Instruments Ltd.,
Loughborough, UK). Wheels were interfaced to a computer and revolutions were recorded in 20 min intervals, continuously for 10 days. The average and the maximal speed, the distance and the duration of running was calculated for the individual mice and then averaged by treatments.

Forepaw grip test The force of forepaw was measured as described earlier [20]. Briefly, when the animals reliably grasped the bar of the grip test meter, they were then gently pulled away from the device. The maximal force before the animal released the bar were digitized at $2 \mathrm{kHz}$ and stored by an online connected computer.

\section{In vitro experiments}

Measurement of muscle force Muscle contractions were measured as described in our previous reports [21]. In brief, fast and slow twitch muscles, EDL and SOL, were removed and placed horizontally in an experimental chamber continuously super fused $(10 \mathrm{ml} / \mathrm{min})$ with Krebs' solution (containing in $\mathrm{mM}: \mathrm{NaCl} 135, \mathrm{KCl} 5$, $\mathrm{CaCl}_{2}$ 2.5, $\mathrm{MgSO}_{4} 1$, Hepes 10, glucose 10, $\mathrm{NaHCO}_{3} 10$; $\mathrm{pH} 7.2$; room temperature) equilibrated with $95 \% \mathrm{O}_{2}$ plus $5 \% \mathrm{CO}_{2}$. One end of the muscle was attached to a rod while the other to a capacitive mechano-electric force transducer. Two platinum electrodes placed adjacent to the muscle were used to deliver short, supramaximal pulses of $2 \mathrm{~ms}$ in duration to elicit single twitches. Force responses were digitized at $2 \mathrm{kHz}$ using Digidata $1200 \mathrm{~A} / \mathrm{D}$ card and stored with Axotape software (Axon Instruments, Foster City, CA, USA). Muscles were then stretched by adjusting the position of the transducer to a length that produced the maximal force response and allowed to equilibrate for $60 \mathrm{~min}$.

Single pulses at $0.5 \mathrm{~Hz}$ were used to elicit single twitches. At least 10 twitches were measured under these conditions from every muscle. The individual force transients within such a train varied by less than $3 \%$ in amplitude, thus the mean of the amplitude of all transients was used to characterize the given muscle. To elicit a tetanus,

Table 1 Body weight changes, muscle/body weights and cross sectional areas

\begin{tabular}{|c|c|c|c|c|c|c|}
\hline & & \multirow[t]{2}{*}{ Control (10) } & \multicolumn{2}{|l|}{ Selenate } & \multicolumn{2}{|l|}{ NanoSe } \\
\hline & & & $0.5 \mathrm{ppm}(6)$ & 5 ppm (8) & $0.5 \mathrm{ppm}(6)$ & 5 ppm (4) \\
\hline Body weight change (g) & & $0.6 \pm 0.2$ & $2.3 \pm 0.2^{*}$ & $3.6 \pm 0.3^{*}$ & $2.5 \pm 0.3^{*}$ & $1.3 \pm 0.3^{*}$ \\
\hline \multirow[t]{2}{*}{ Muscle/body weight (\%) } & EDL & $0.038 \pm 0.003(14)$ & $0.050 \pm 0.01^{\#}(11)$ & $0.045 \pm 0.001(10)$ & $0.051 \pm 0.001^{\#}(10)$ & $0.049 \pm 0.001^{\#}(7)$ \\
\hline & SOL & $0.038 \pm 0.001(10)$ & $0.056 \pm 0.002^{\#}(12)$ & $0.046 \pm 0.002^{\#}(15)$ & $0.056 \pm 0.001^{\#}(10)$ & $0.049 \pm 0.004^{\#}(7)$ \\
\hline \multirow[t]{2}{*}{ Cross sectional area $\left(\mathrm{mm}^{2}\right)$} & EDL & $1.75 \pm 0.13$ & $1.95 \pm 0.16$ & $1.87 \pm 0.11$ & $1.84 \pm 0.13$ & $1.58 \pm 0.15$ \\
\hline & SOL & $1.49 \pm 0.13$ & $1.54 \pm 0.79$ & $1.25 \pm 0.06$ & $1.68 \pm 0.20$ & $1.24 \pm 0.11$ \\
\hline
\end{tabular}

*denotes significant increase $(P<0.05)$ compared to the starting body weight

\#denotes significant difference $(P<0.05)$ compared to control

Numbers in parenthesis denote the number of animals or muscles 
single pulses were applied with a frequency of $200 \mathrm{~Hz}$ for $200 \mathrm{~ms}$ (EDL) or $100 \mathrm{~Hz}$ for $500 \mathrm{~ms}$ (SOL). Duration of individual twitches and tetani were determined by calculating the time between the onset of the transient and the relaxation to $90 \%$ of maximal force.

Isolation of single skeletal muscle fibers All calcium concentration measurements were carried out on skeletal muscle fibers from the FDB muscle of the mouse. Calcium free Tyrode's solution $(145 \mathrm{mM} \mathrm{NaCl}, 2.7 \mathrm{mM} \mathrm{KCl}, 1 \mathrm{mM}$ $\mathrm{MgCl}_{2}$, and $11.8 \mathrm{mM}$ Hepes, $\mathrm{pH}$ 7.4) was used during the dissection of the muscle. Single muscle fibers from FDB were enzymatically dissociated in minimal essential media containing $0.2 \%$ Type I collagenase (Sigma) at $37{ }^{\circ} \mathrm{C}$ for 65 min [22, 23]. To release single fibers, the FDB muscles were triturated gently in normal Tyrode's solution $\left(1.8 \mathrm{mM} \mathrm{CaCl}_{2}\right)$. The fibers were then placed in culture dishes and stored at $4 .{ }^{\circ} \mathrm{C}$ in refrigerator until use.

Whole cell intracellular $\mathrm{Ca}^{2+}$ concentration measurement Intracellular $\mathrm{Ca}^{2+}$ concentration $\left(\left[\mathrm{Ca}^{2+}\right]_{\mathrm{i}}\right)$ was monitored using Fura-2 in acetoxymethyl form as described previously [22, 24]. Briefly, isolated FDB fibers were mounted on a laminin-coated cover slip and loaded with $5 \mu \mathrm{M}$ Fura-2 AM for $60 \mathrm{~min}$. Fibers were then equilibrated in Tyrode's solution for $30 \mathrm{~min}$ at room temperature. Cover slips with Fura-2 loaded fibers were placed on the stage of an inverted fluorescence microscope (Diapoth, Nikon, Tokyo, Japan). The excitation wavelength was altered between 340 and $380 \mathrm{~nm}$ by a microcomputer-controlled dual-wavelength monochromator (Deltascan, Photon Technology International, New Brunswick, NJ), whereas the emission was monitored at $510 \mathrm{~nm}$ using a photomultiplier at $10 \mathrm{~Hz}$ acquisition rate of the ratios at $22{ }^{\circ} \mathrm{C}^{\circ} \mathrm{Ca}^{2+}$ transients were evoked by $\mathrm{KCl}$ depolarization. Fibers were permanently washed with Tyrode's solution using a background perfusion system, whilst the depolarizing solution $(120 \mathrm{mM} \mathrm{NaCl}$ was replaced by $120 \mathrm{mM} \mathrm{KCl}$ ) was applied through a local perfusion system, which was positioned in close proximity to the measured fiber. Intracellular calcium concentration was calculated from the ratio of measured fluorescence intensities at 340 and $380 \mathrm{~nm}$ using an in vivo calibration as described in our earlier report [22].

Confocal intracellular $\mathrm{Ca}^{2+}$ concentration measurement Changes in $\left[\mathrm{Ca}^{2+}\right]_{\mathrm{i}}$ were also monitored using Rhod$2 \mathrm{AM}$ as described previously [20]. Briefly, after dissociation, FDB fibers were placed into culture dish with Tyrode's solution. Depolarization-evoked calcium transients were measured at $22{ }^{\circ} \mathrm{C}$ using a confocal laser scanning microscope system (Zeiss 5 Live, Oberkochen, Germany) after loading the fibers with $20 \mu \mathrm{M}$ Rhod-2 AM for $15 \mathrm{~min}$ at room temperature. Individual action potentials were evoked by applying supra-threshold $2 \mathrm{~ms}$ long square pulses (S88 Stimulator, Grass Technologies, Warwick, RI, USA) through a pair of platinum electrodes placed close to the fiber. Line-scan images (512 pixels/line) were used to monitor the fluorescence intensity changes at $1 \mathrm{~ms} /$ line and using a 40x water immersion objective. Rhod-2 was excited with a $\mathrm{HeNe}$ ion laser at $543 \mathrm{~nm}$, emission was detected with a $550 \mathrm{~nm}$ long pass filter. To obtain the time-course of Rhod-2 fluorescence change $\left(\mathrm{F}_{\text {rhod }}\right)$, corresponding data points (usually 10-15) in the line-scan images were averaged in the spatial domain. Resting fluorescence was determined as the average fluorescence before the depolarization. Changes in $\left[\mathrm{Ca}^{2+}\right]_{i}$ were then calculated using the formula

$$
\begin{aligned}
{\left[\mathrm{Ca}^{2+}\right]_{\mathrm{i}}=} & \mathrm{Kd}_{\text {rhod }} \bullet\left(1 / \mathrm{k}_{\text {off, rhod }} \bullet \mathrm{dF}_{\text {rhod }} / \mathrm{dt}+\mathrm{F}_{\text {rhod }}-\mathrm{F}_{\text {rhod, min }}\right) \\
& /\left(\mathrm{F}_{\text {rhod, max }}-\mathrm{F}_{\text {rhod }}\right)
\end{aligned}
$$

where $F_{\text {rhod,max }}$ and $F_{\text {rhod,min }}$ were determined in our laboratory, while other parameters $\left(\mathrm{Kd}_{\text {rhod }}=\mathrm{k}_{\text {off,rhod }} /\right.$ $\mathrm{k}_{\text {on,rhod }}$ is the dissociation constant, $\mathrm{k}_{\text {off,rhod }}$ and $\mathrm{k}_{\text {on,rhod }}$ the backward and forward rate constant for the calciumdye reaction, respectively) for Rhod-2 were taken from Escobar and co-workers [25].

Calculation of calcium release from the SR The $\mathrm{Ca}^{2+}$ release flux (FL) was defined as the first time derivative of the sum of the $\mathrm{Ca}^{2+}$ in the myoplasmic space and that transported back into the SR, as described earlier:

$$
\mathrm{FL}=\mathrm{d}\left(\mathrm{Ca}_{\text {total }}+\mathrm{Ca}_{\text {transp }}\right) / \mathrm{dt},
$$

where $\mathrm{Ca}_{\text {total }}$ is the total $\mathrm{Ca}^{2+}$ in the myoplasm, while $\mathrm{Ca}_{\text {transp }}$ is the amount of $\mathrm{Ca}^{2+}$ transported by the $\mathrm{Ca}^{2+}$ pumps [15]. $\mathrm{Ca}_{\text {total }}$ was estimated as the sum of free $\mathrm{Ca}^{2+}$ and the amount of $\mathrm{Ca}^{2+}$ bound to intracellular binding sites.

In Eq. 2. $\mathrm{Ca}_{\text {transp }}$ was considered proportional to the relative saturation of the pumps. Removal parameters were taken from the literature [26] and used to calculate the binding of $\mathrm{Ca}^{2+}$ to intracellular binding sites as described in our earlier reports [27].

Preparation of cell extracts Freshly prepared EDL and soleus muscles were mechanically homogenized in buffer (20 mM Tris-Cl, 5 mM EGTA, 1 mM 4-(2-aminoethyl) benzenesulphonyl fluoride, $20 \mu \mathrm{M}$ leupeptin, $\mathrm{pH}$ 7.4; all from Sigma) and disrupted by sonication on ice. Protein content of the samples was measured by a modified bicinchoninic acid (BCA) protein assay (Pierce, Rockford, IL, USA) using BSA as a standard.

Western blot analysis For Western blot analysis (SDSPAGE) total muscle lysates of EDL and SOL were prepared by adding $1 / 5$ volume of fivefold concentrated electrophoresis sample buffer (310 mM Trise- $\mathrm{HCl} \mathrm{pH}$ 6.8, 10 \% SDS, 
50 \% glycerol, $100 \mathrm{mM}$ DTT, $0.01 \%$ bromophenol blue) to muscle lysates and boiled for $10 \mathrm{~min}$ at 80 C. $30 \mu \mathrm{g}$ of protein was separated by $7.5 \%$ SDS-PAGE gel for immunological detection of selenoprotein $\mathrm{N}$. Proteins were transferred electrophoretically to nitrocellulose membranes. After blocking in $5 \%$ non-fat dry milk in PBS, membranes were incubated with primary antibodies overnight at $4{ }^{\circ} \mathrm{C}$ as follows: rabbit polyclonal anti-selenoprotein $\mathrm{N}$ antibody raised against amino acids 293-452 mapping within an internal region of selenoprotein $\mathrm{N}$ of human origin in 1:200, (Santa Cruz Biotechnology, INC, Santa Cruz, CA, USA); and rabbit polyclonal anti-actin antibody in 1:500 (Santa Cruz Biotechnology, Inc., Santa Cruz, CA, USA). After washing for $30 \mathrm{~min}$ in PBST, membranes were incubated with the HRP-conjugated secondary antibody (Bio-Rad, Hercules, CA, USA) in 1:1000 dilution in PBS containing $5 \%$ non-fat dry milk for $1 \mathrm{~h}$. Signals were detected by enhanced chemiluminescence reaction (Millipore, Billerica, MA, USA) according to the instructions of the manufacturer.

Statistical analysis Pooled data were expressed as mean \pm standard error of the mean (SEM). The differences between control and animals on increased selenium diet were assessed using one way analysis of variance (ANOVA) and all pair wise multiple comparison procedures (StudentNewman-Keuls Method) with Prism (GraphPad Software, San Diego, CA, USA). F-test was used to test the significance and a $P$ value of less than 0.05 was considered statistically significant.

\section{Results}

\section{In vivo experiments}

Mice on selenium supplemented diet gained weight during the two weeks of Se-feeding while control animals remained almost the same weight (Table 1). To check the in vivo muscle performance of the animals, 4 mice were used from all groups (control, 0.5 and $5 \mathrm{ppm}$ selenate and NanoSe) in grip tests. Mice from selenium-treated groups did not perform significantly better than the control animals in these tests. That is, the maximal force after normalization to body weight remained the same after 14 days on selenium diet (Table 2).

The voluntary wheel experiments showed a positive effect of selenium treatment on the performance of

Table 2 Maximal grip force $(\mathrm{mN})$ at the beginning and at the end of experiment

\begin{tabular}{lcccccc}
\hline & Control (4) & \multicolumn{2}{l}{ Selenate } & & NanoSe & \\
\cline { 3 - 4 } \cline { 6 - 6 } & & $0.5 \mathrm{ppm}(4)$ & $5 \mathrm{ppm}(4)$ & & $0.5 \mathrm{ppm}(4)$ & $5 \mathrm{ppm}(4)$ \\
\hline Beginning $^{\mathrm{a}}$ & $507 \pm 19$ & $534 \pm 9$ & $455 \pm 9$ & & $493 \pm 17$ & $571 \pm 8$ \\
End $^{\mathrm{a}}$ & $504 \pm 16$ & $509 \pm 7$ & $474 \pm 14$ & & $502 \pm 11$ & $553 \pm 9$ \\
\hline
\end{tabular}

Numbers in parenthesis denote the number of animals. ${ }^{\text {a Average of values }}$ measured on the first and last day of 14 days special diet animals, but only in the higher (5 ppm) concentration. After 2-3 days accommodation in the special cage the average and maximal speed of running stabilized on a given level in the control group, while they increased continuously in the $5 \mathrm{ppm}$ selenium treated mice (Fig. 1). The total distance covered was significantly higher in the 5 ppm selenium feed groups (Table 3). In addition, they spent more time in the wheel than control mice did at the end of $5 \mathrm{ppm}$ selenium supplementation. Overall, this experiment clearly indicated, that there is a positive effect on voluntary muscle performance of selenium treatment in mice. To clarify the underlying mechanisms the steps in EC coupling were investigated in detail.

\section{In vitro experiments}

\section{Force measurement}

In order to determine whether administration of selenium might alter muscle functions directly, the effects of selenium supplementation on in vitro muscle strength were investigated. A significant difference was found in

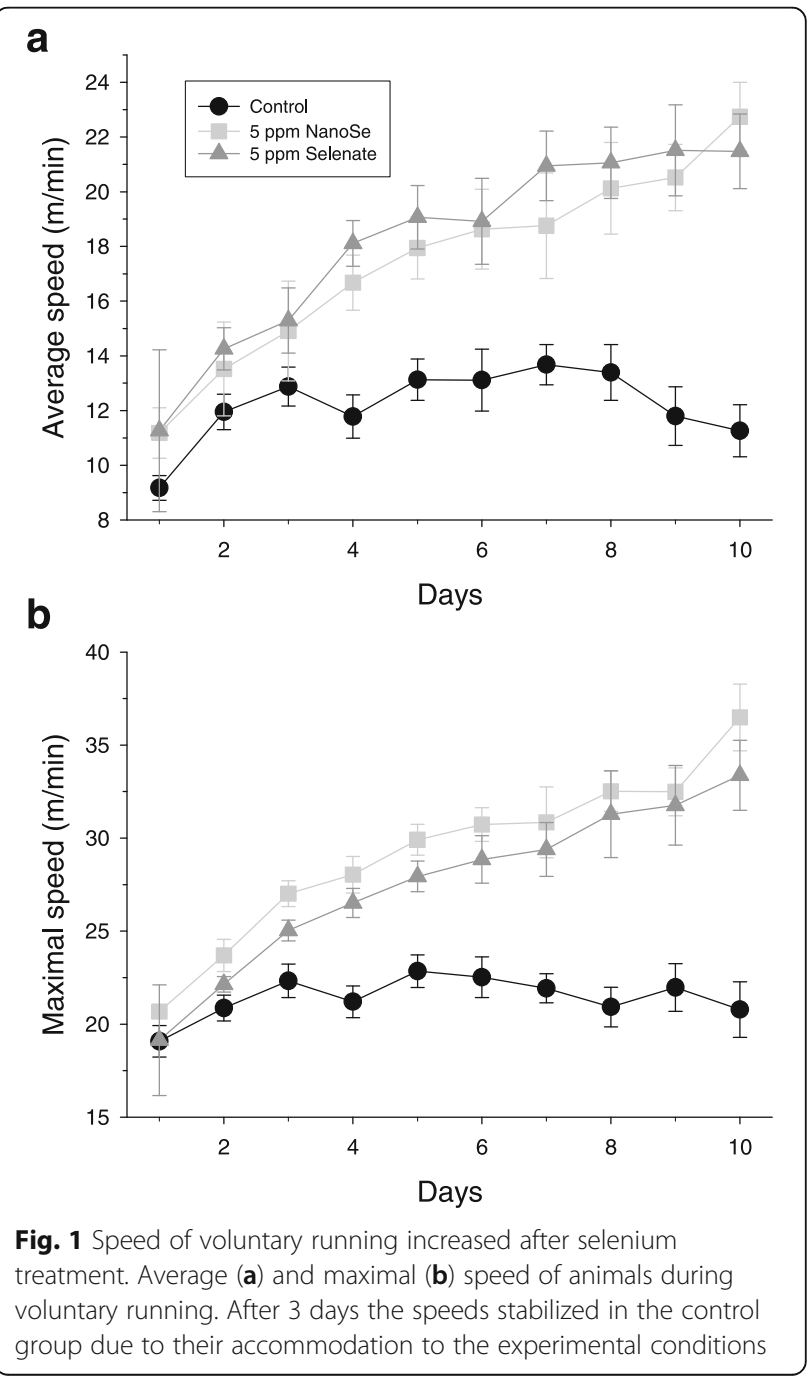


Table 3 Parameters of voluntary running at the beginning and at the end of experiment

\begin{tabular}{|c|c|c|c|c|c|c|}
\hline & & \multirow[t]{2}{*}{ Control (8) } & \multicolumn{2}{|l|}{ Selenate } & \multicolumn{2}{|l|}{ NanoSe } \\
\hline & & & $0.5 \mathrm{ppm}(8)$ & 5 ppm (8) & 0.5 ppm (8) & 5 ppm (8) \\
\hline \multirow[t]{2}{*}{ Distance (m/day) } & Beginning $^{a}$ & $5313 \pm 406$ & $5280 \pm 548$ & $4959 \pm 226$ & $5343 \pm 699$ & $4994 \pm 301$ \\
\hline & End $^{\mathrm{a}}$ & $4592 \pm 354$ & $4910 \pm 1056$ & $6642 \pm 168^{\# \#, * * *}$ & $5178 \pm 612$ & $7820 \pm 851^{\#, *}$ \\
\hline \multirow[t]{2}{*}{ Duration (min/day) } & Beginning $^{a}$ & $334 \pm 16$ & $306 \pm 17$ & $315 \pm 10$ & $339 \pm 17$ & $335 \pm 16$ \\
\hline & End $^{\mathrm{a}}$ & $253 \pm 10^{* *}$ & $264 \pm 43$ & $302 \pm 4^{\# \#, *}$ & $268 \pm 26^{*}$ & $333 \pm 17^{\# \#}$ \\
\hline \multirow[t]{2}{*}{ Average speed (m/min) } & Beginning $^{a}$ & $11.3 \pm 1.1$ & $12.5 \pm 0.8$ & $13.6 \pm 1.2$ & $11.7 \pm 0.5$ & $13.2 \pm 1.1$ \\
\hline & End $^{a}$ & $12.0 \pm 0.5$ & $13.9 \pm 0.7^{\#}$ & $21.4 \pm 0.1^{\# \# \#, * * *}$ & $14.7 \pm 0.3^{\# \#, * * *}$ & $21.1 \pm 0.8^{\# \# \#, * * *}$ \\
\hline \multirow[t]{2}{*}{ Maximal speed (m/min) } & Beginning $^{a}$ & $20.8 \pm 0.9$ & $23.2 \pm 0.9$ & $22.1 \pm 1.7$ & $20.5 \pm 1.6$ & $23.8 \pm 1.8$ \\
\hline & End $^{\mathrm{a}}$ & $21.2 \pm 0.4$ & $23.3 \pm 1.3$ & $32.1 \pm 0.6^{\# \# \#, * * *}$ & $23.2 \pm 1.1$ & $33.8 \pm 1.3^{\# \# \#, * *}$ \\
\hline
\end{tabular}

\#,\# and \#\#\# denotes significant difference $(P<0.05,0.01$ and 0.001$)$ compared to control

* and ${ }^{*}$ denotes significant difference $(P<0.05$ and 0.01$)$ compared to beginning

Numbers in parenthesis denote the number of animals

${ }^{a}$ Average of values measured on the first three and last three day of 10 days special diet

the mean amplitude of the single twitches in both EDL (Fig. 2a,b) and in SOL (Fig. 3a,b) between selenium supplemented and the control animals (Table 4). Similarly, significant difference was found in tetani (Figs. 2c,d and $3 \mathrm{c}, \mathrm{d})$. In lower concentration of selenium $(0.5 \mathrm{ppm})$ the average amplitude of twitches and tetani was significantly higher than in control conditions only in SOL.
There were no differences in the twitch/tetanus ratio between the selenium supplemented and the control muscles (data not shown). There was no difference in the time-to-peak values except in SOL of the $0.5 \mathrm{ppm}$ selenate treated animals, where it was significantly higher than in control mice. Furthermore, selenate increased fatigue resistance in SOL after 150 tetani (see

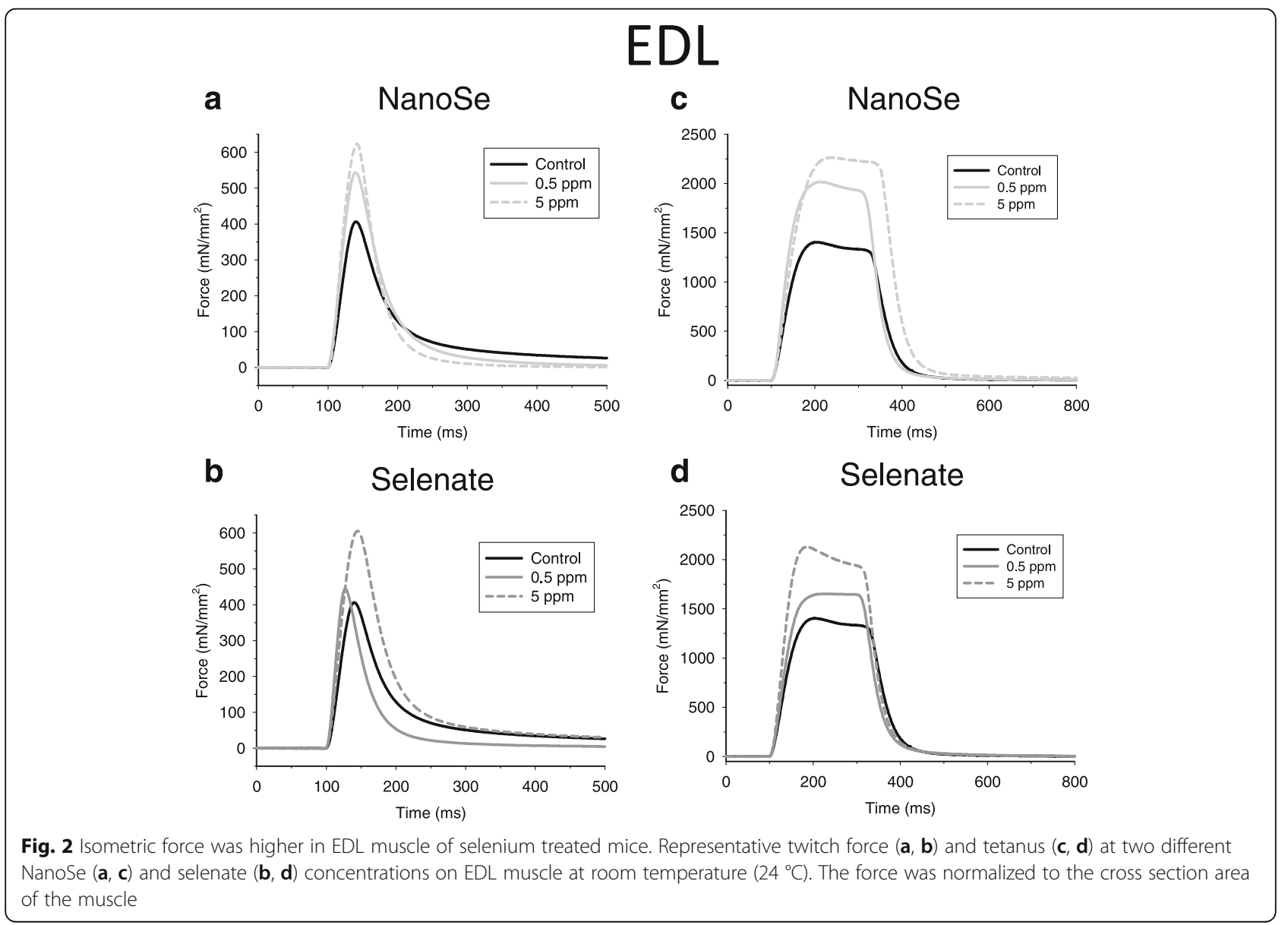




\section{Soleus}
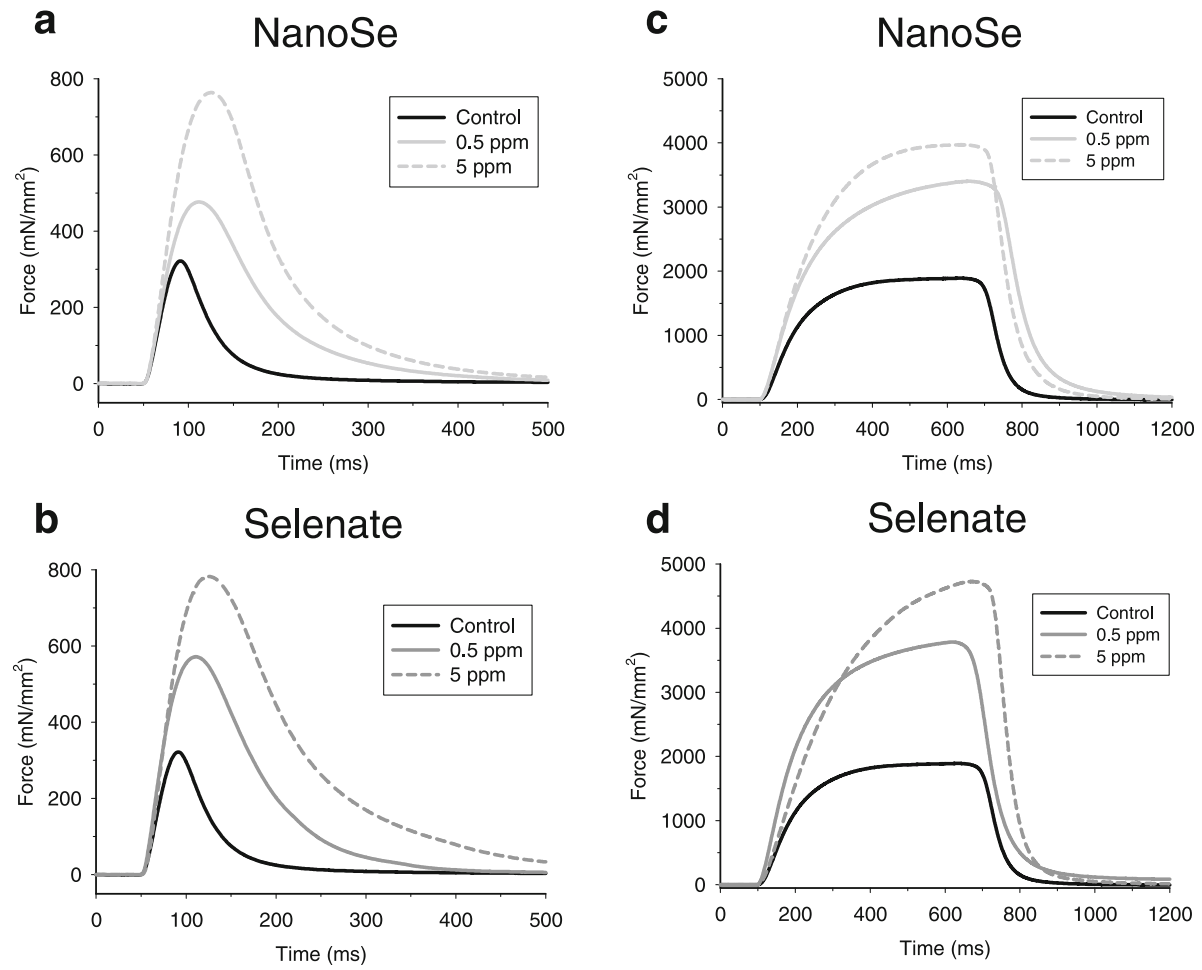

Fig. 3 Isometric force of SOL muscle was higher in selenium treated mice. Representative twitch force $(\mathbf{a}, \mathbf{b})$ and tetanus $(\mathbf{c}, \mathbf{d})$ at two different NanoSe $(\mathbf{a}, \mathbf{c})$ and selenate $(\mathbf{b}, \mathbf{d})$ concentrations on $\mathrm{SOL}$ muscle at room temperature $\left(24^{\circ} \mathrm{C}\right)$

Additional file 1: Figure S2). In addition, we observed a significant increase in all but one relative EDL and SOL muscle weight (Table 1).

\section{Intracellular $\mathrm{Ca}^{2+}$ concentration changes after selenium treatment}

The effects of the selenium treatments on the calcium homeostasis were examined in isolated, single FDB skeletal muscle fibers. Figure 4a presents representative calcium transients evoked by depolarization using $120 \mathrm{mM} \mathrm{KCl}$ in the presence of normal $(1.8 \mathrm{mM})$ extracellular calcium concentration. Selenium already in $0.5 \mathrm{ppm}$ concentration increased the amplitude of calcium transients. Figure $4 \mathrm{~b}$ plots pooled data to confirm that the selenium treatment had a little, but statistically significant increasing effects on the resting $\left[\mathrm{Ca}^{2+}\right]_{\mathrm{i}}$ suggesting that the calcium leak from and the extrusion into the extracellular environment could be affected under these conditions. On the other hand, depolarizationevoked calcium transients were notably higher in selenium treated than in control fibers (Fig. 4c). Selenate almost doubled the amplitude of the calcium transients. The same concentration of NanoSe also increased it slightly, albeit this increase was not as pronounced.
Further examination of the transients proved that the rate of calcium release from the SR was significantly higher after both kinds of selenium treatments (Fig. 4d).

\section{Action potential-evoked calcium transients in FDB fibers}

Field stimulation-induced global calcium transients were also measured on FDB fibers. These calcium transients were visualized using laser scanning confocal microscopy in the line-scan mode. Figure 5 displays representative fluorescence intensity changes during single pulses (panel A) from control (left), $0.5 \mathrm{ppm}$ selenate (middle) and NanoSe (right) treated mice. The spatial profile of the transients was homogenous in all groups showing a normal propagation of the depolarization in the T-tubular system.

To analyze the calcium transients, the line-scans were normalized to background fluorescence and 10-15 points of the images in the spatial domain were averaged and transformed to calcium concentration (Eq. 1). Then the total amount of calcium released $\left(\mathrm{Ca}_{\text {total }}\right)$ and the calcium release flux (FL) through the RyRs was calculated (Eq. 2). It is clearly visible in Fig. 5, that the change in intracellular calcium concentration (panel B and D) as well as the total calcium released into the myoplasm (panel E), and the corresponding calcium release flux (panel F) was 
Table 4 Average parameters of twitch and tetanus of EDL and soleus muscles

\begin{tabular}{|c|c|c|c|c|c|c|c|c|c|c|c|}
\hline & \multirow{3}{*}{$\begin{array}{l}\text { Contraction } \\
\text { type }\end{array}$} & \multirow{2}{*}{\multicolumn{2}{|c|}{ Control }} & \multicolumn{4}{|l|}{ Selenate } & \multicolumn{4}{|l|}{ NanoSe } \\
\hline & & & & \multicolumn{2}{|l|}{$0.5 \mathrm{ppm}$} & \multicolumn{2}{|l|}{$5 \mathrm{ppm}$} & \multicolumn{2}{|l|}{$0.5 \mathrm{ppm}$} & \multicolumn{2}{|l|}{$5 \mathrm{ppm}$} \\
\hline & & $\mathrm{EDL}$ & $\mathrm{SOL}$ & $\overline{E D L}$ & SOL & $\overline{\mathrm{EDL}}$ & SOL & $\overline{\mathrm{EDL}}$ & SOL & EDL & SOL \\
\hline \multirow{2}{*}{$\begin{array}{l}\text { Peak } \\
\left(\mathrm{mN} / \mathrm{mm}^{2}\right)\end{array}$} & Single twitch & $0.72 \pm 0.09$ & $0.52 \pm 0.10$ & $0.68 \pm 0.11$ & $0.93 \pm 0.13^{*}$ & $0.98 \pm 0.08^{*}$ & $1.06 \pm 0.15^{*}$ & $0.82 \pm 0.13$ & $1.04 \pm 0.20^{*}$ & $0.96 \pm 0.08^{*}$ & $1.26 \pm 0.12^{*}$ \\
\hline & Tetanus & $2.55 \pm 0.39$ & $2.72 \pm 0.41$ & $2.81 \pm 0.09$ & $5.72 \pm 0.73^{*}$ & $3.81 \pm 0.46^{*}$ & $6.46 \pm 0.90^{*}$ & $3.29 \pm 0.44$ & $5.36 \pm 1.31^{*}$ & $3.97 \pm 0.56^{*}$ & $7.12 \pm 0.37^{*}$ \\
\hline \multirow{2}{*}{$\begin{array}{l}\text { Time to } \\
\text { peak (ms) }\end{array}$} & Single twitch & $26.7 \pm 2.0$ & $63.5 \pm 4.1$ & $28.9 \pm 1.6$ & $68.4 \pm 3.2$ & $30.0 \pm 1.3$ & $68.2 \pm 2.7$ & $29.4 \pm 1.5$ & $65.7 \pm 3.4$ & $27.9 \pm 0.73$ & $69.4 \pm 7.5$ \\
\hline & Tetanus & $142.2 \pm 15.6$ & $475.2 \pm 21.2$ & $140.1 \pm 25.6$ & $530.5 \pm 4.2^{*}$ & $144.1 \pm 10.6$ & $458.4 \pm 45.2$ & $128.1 \pm 14.4$ & $475.5 \pm 49.9$ & $147.2 \pm 12.6$ & $493.3 \pm 27.8$ \\
\hline $\begin{array}{l}\text { Fatigue after } \\
150 \text { tetani (\%) }\end{array}$ & & $31.8 \pm 5.4$ & $29.5 \pm 2.7$ & $38.8 \pm 10.5$ & $43.3 \pm 3.9$ & $41.1 \pm 3.6$ & $47.5 \pm 5.6$ & $42.9 \pm 3.2$ & $45.7 \pm 6.2$ & $43.9 \pm 6.3$ & $49.7 \pm 8.0$ \\
\hline \multirow{2}{*}{$\begin{array}{l}\text { Number of } \\
\text { muscles } \\
\text { tested }\end{array}$} & Single twitch & 14 & 10 & 11 & 12 & 14 & 15 & 10 & 10 & 7 & 7 \\
\hline & Tetanus & 14 & 15 & 5 & 8 & 14 & 11 & 8 & 8 & 5 & 6 \\
\hline
\end{tabular}

*denotes significant difference $(P<0.05)$ compared to control. The amplitude of the $150^{\text {th }}$ tetani were normalized to the first tetanus 

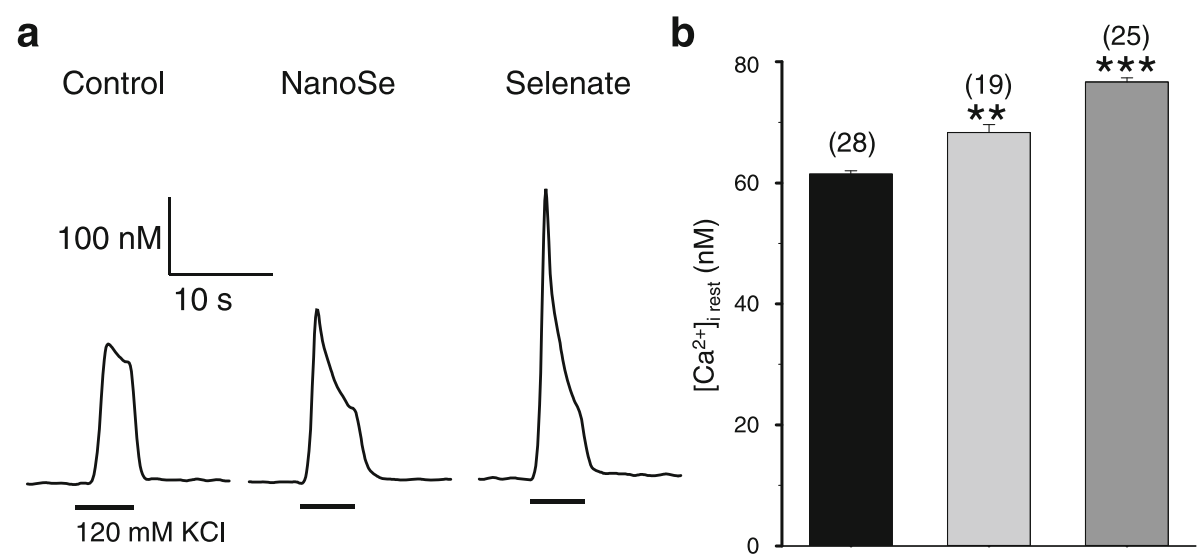

C

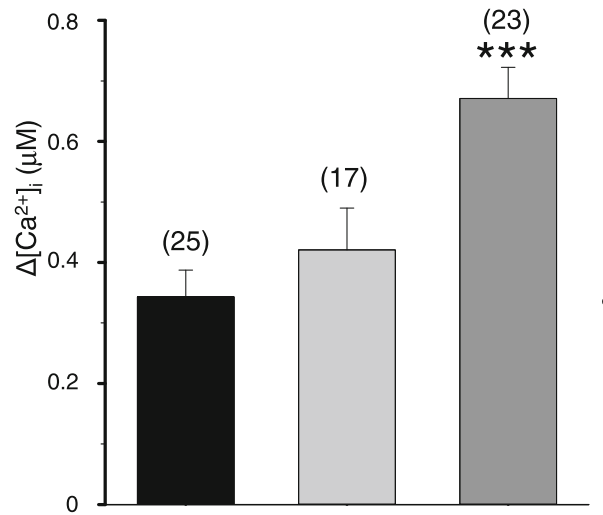

d

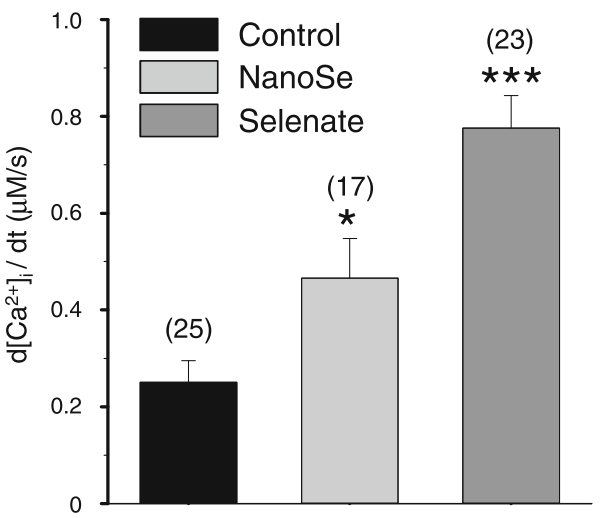

Fig. 4 Selenium treatment augmented $\mathrm{KCl}$ depolarization evoked $\mathrm{Ca}^{2+}$ transients and resting $\left[\mathrm{Ca}^{2+}\right]_{\mathrm{i}}$ in FDB fibers. Depolarization evoked changes in intracellular calcium concentration in FDB muscle (a) of control (left), 0.5 ppm NanoSe (middle) and 0.5 ppm selenate (right) feed mice. Average values of resting $\left[\mathrm{Ca}^{2+}\right]_{\mathrm{i}}(\mathbf{b})$, change in $\left[\mathrm{Ca}^{2+}\right]_{\mathrm{i}}\left(\Delta\left[\mathrm{Ca}^{2+}\right]_{\mathrm{i}}\right)(\mathbf{c})$ and maximal rate of rise of the transients $(\mathbf{d})$. Numbers in parenthesis give the number of fibers investigated. * and *** denote significant difference from control at levels of $P<0.05$ and $P<0.001$, respectively

increased significantly in selenate treated mice. The amount of released calcium showed an about 60 and $100 \%$ increase in $0.5 \mathrm{ppm}$ NanoSe and selenate fed mice, respectively. The data presented in Fig. 5 clearly demonstrate that depolarization-evoked calcium release from the SR was significantly higher in selenium fed mice.

\section{Western blot analysis of selenoprotein expression}

Finally the expression level of selenoprotein $\mathrm{N}$ in EDL and SOL muscles from control mice and mice fed with NanoSe or selenate was determined. In 0.5 ppm concentration both selenium compounds increased significantly the SelN expression only in EDL muscle (Fig. 6a and b). However, in 5 ppm concentration both selenium compounds increased SelN expression significantly in both (EDL and SOL) muscle samples (data not shown).

\section{Discussion}

The results of our study provide novel insights into the effects of dietary selenium on skeletal muscle functions.
New findings of the study are the direct effects of selenium supplementation on skeletal muscle function.

\section{Selenoprotein in selenium fed animals}

One explanation of the increased force we observed on the selenium fed mice could be the alteration of the expression of selenoprotein N. Arbogast and Ferreiro [16] have shown that SelN deficiency is associated with abnormalities in intracellular $\mathrm{Ca}^{2+}$ handling, potentially related with RyR1 dysfunction in myotubes. Another study on rats presented that the lack of selenoprotein causes diaphragm muscle weakness by lowering diaphragmatic glutathione peroxidase activity, and then these animals are subjected to the oxidative stress of resistive loading [28].

We examined the selenoprotein $\mathrm{N}$ expression of muscles and found it markedly increased in EDL (Fig. 6). This is in good agreement with previous studies $[29,30]$, where selenium supplementation caused a similar increase in the level of several selenoproteins. In our experiments a low dose of selenium produced favorable effects on skeletal 
a

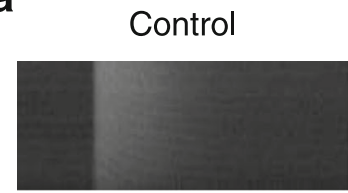

b

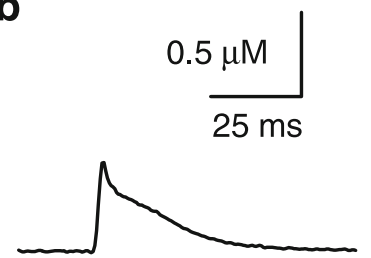

C

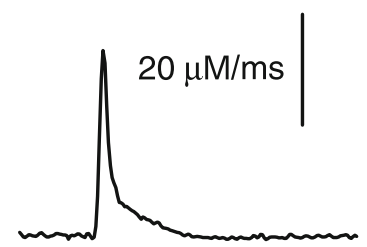

d

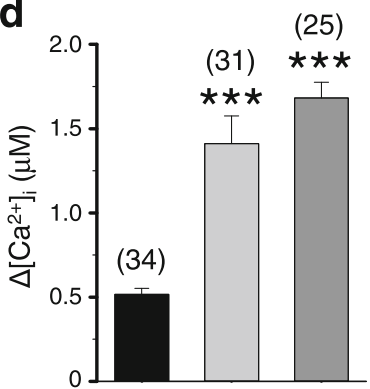

NanoSe
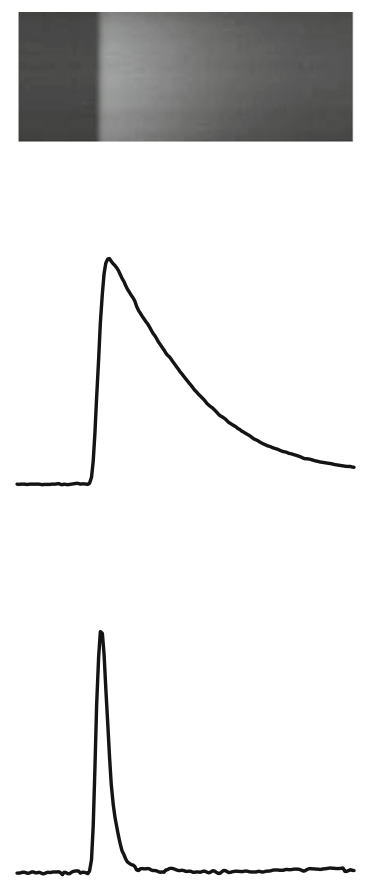

e

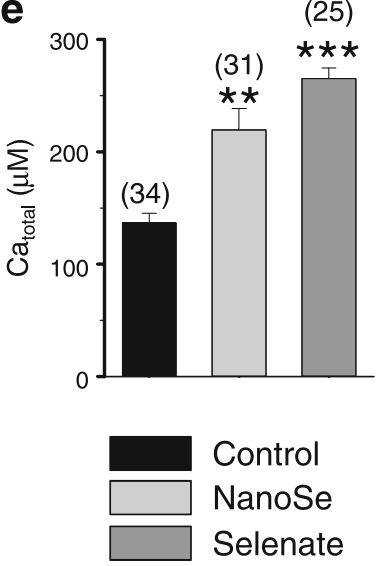

Selenate
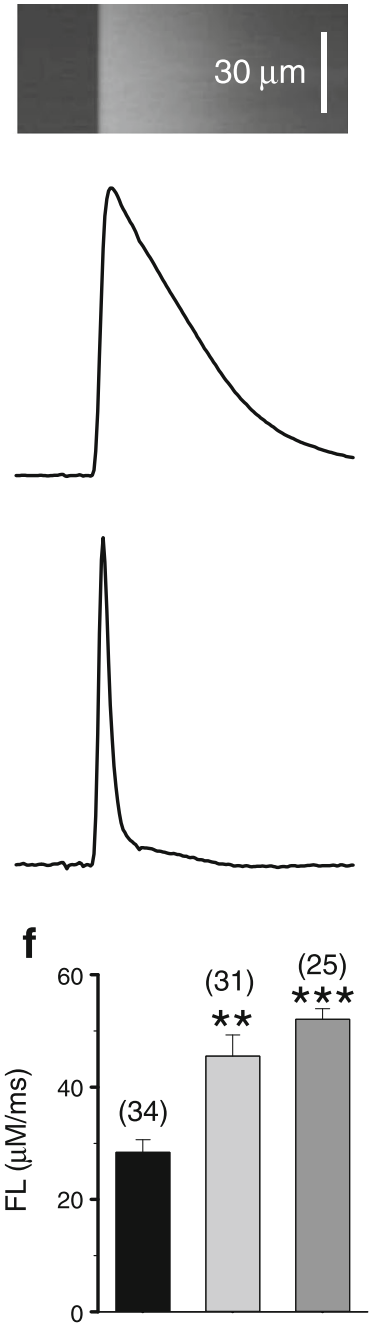

Fig. 5 Depolarization evoked $\Delta\left[\mathrm{Ca}^{2+}\right]_{i}$ and release flux were higher in FDB fibers of selenium treated mice. Line-scan images of fluorescence intensity changes evoked by single depolarization (a) in FDB of control (left), 0.5 ppm NanoSe (middle) and 0.5 ppm selenate (right) feed mice. Intracellular calcium concentration changes (b) calculated from the $\mathrm{Ca}^{2+}$ transient in panel (a). The corresponding calcium release flux through the RyR (c) calculated from the curves in panel (b). The averages of the change in intracellular calcium concentration (d), the total calcium released into the myoplasm (e), and the corresponding calcium release flux ( $\mathbf{f}$. ${ }^{* *}$ and ${ }^{* * *}$ show significant difference from control at levels of $P<0.01$ and $P<0.001$, respectively. Numbers in parenthesis give the number of fibers investigated. Measurement conditions: $8000 \times 50$ pixel, $0.5 \mu \mathrm{s} /$ line, $0.66 \mu \mathrm{m} /$ pixel at room temperature $\left(24^{\circ} \mathrm{C}\right)$

muscle functions, presumably by increasing the intracellular availability of selenium for selenoprotein $\mathrm{N}$ synthesis and stimulating SelN expression.

\section{Toxicity and efficacy}

Several animal studies showed long time ago that Se deficiency may result in damage to the heart, liver, kidneys, lung and skeletal muscle [7, 29, 31, 32]. On the contrary, only recent investigations aimed to explore the effects of increased Se supplementation [13, 14, 29, 30], but none of them studied skeletal muscle functions. The doses used in our study $(0.5$ and $5 \mathrm{mg} / \mathrm{kg})$ were similar to doses used in a previous study [13] in which both were shown not to be toxic in mice. Though in this study both selenium compounds decreased the white blood cell number and the weight of spleen in the higher concentration, only selenate decreased the weight of liver. These changes were significant but did not lead to the death of animals. 


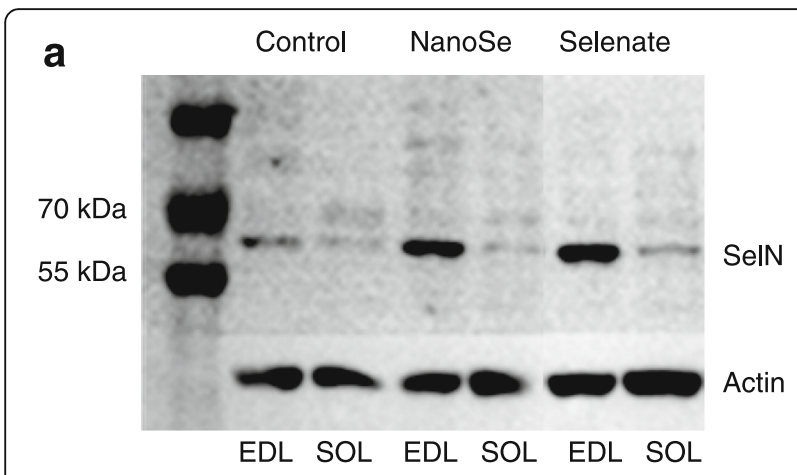

b

$$
\text { NanoSe }
$$

Selenate

(3)

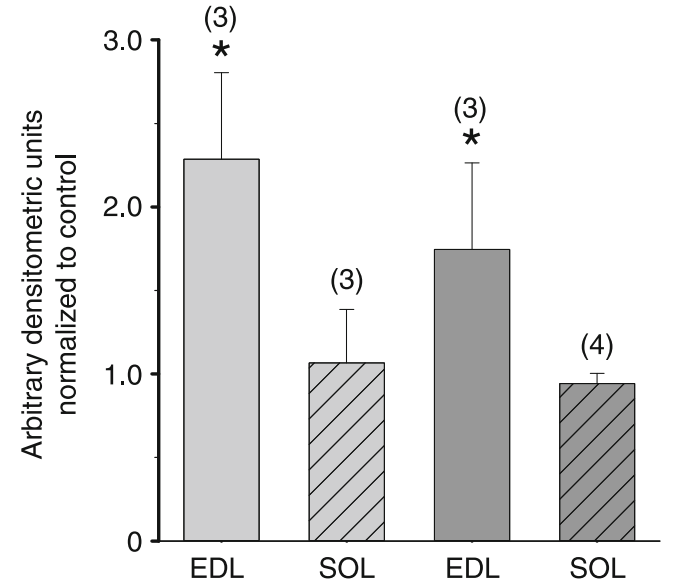

Fig. 6 Selenoprotein $N$ expression increased in selenium treated mice. Representative Western blot image showing the expression of selenoprotein $\mathrm{N}$ in EDL and SOL muscles from a control mouse and a mouse fed with 0.5 ppm NanoSe or selenate for two weeks (a). Actin was used as loading control. Quantified expression of selenoprotein N in EDL and SOL muscles of selenium treated mice normalized to actin and control (b). * denotes significant difference from control at level $P<0.05$. Numbers in parenthesis give the number of animals fed with $0.5 \mathrm{ppm}$ NanoSe or selenate

We point out that all animals survived the 2-week-long treatment in our experiments and a minor increase in body weight was observed proving the sub toxic dose of selenium. On the other hand, the higher Se dose $(5 \mathrm{mg} /$ $\mathrm{kg}$ ) caused significant decrease in body weight of rats, but not in mice after 14 days [33]. However, a 12 weeks application of $0.5 \mathrm{mg} / \mathrm{kg}$ sodium selenite induced reactive myocardial fibrosis and systolic dysfunction in mice [29]. This suggest that there is a narrow range between the effective and toxic concentration of selenium and its accumulation needs also to be considered in further therapy.

We did not find obvious difference in the efficacy of the two selenium compounds. In in vivo experiments they were equally effective. NanoSe increased more the force in EDL than selenate, however their efficacy was the same in soleus. This can be explained considering the fact that NanoSe increased the SelN expression in EDL more than selenate, whereas this effect was equal in the slow muscle. Surprisingly selenate increased more the amplitude of calcium release from the SR. Similar bipolar effects were observed in a recent study [34] where the efficacy and toxicity of selenium nanoparticles and selenium dioxide were compared. Whereas the former showed higher scavenging activity and lower cytotoxicity in cell culture, the latter had higher electron-donating activity.

\section{Regulation of EC-coupling}

It has been known for a long time that muscular activity increases the production of reactive oxygen species, and this seems to correlate with the loss of muscle function [3537]. Exogenous antioxidants given prior to the onset of muscle activity, delay or minimize the decline in muscle performance and decrease the effects of the oxidative stress $[37,38]$. However, the relationship between the function of the different cellular antioxidant systems and the performance of skeletal muscles remains unclear. It was shown recently that reactive oxygen species is a physiological regulator of skeletal RyR [39]. Oxidation of RyR resulted in increased RyR activity and $\mathrm{Ca}^{2+}$ leak from the sarcoplasmic reticulum in rest. This leads to reduced SR calcium content and finally decreased force production. The antioxidant effect of selenium can reverse this and result in a higher force as observed here. Similar effects were found in a study on diabetic rats demonstrating a cardio protective action of selenium and suggesting that one of the underlying mechanisms is the protection of cardiac ryanodine receptor $\mathrm{Ca}^{2+}$ release channel against oxidative stress [40].

SelN can also regulate the calcium level in the SR via enhancing SERCA activity by reducing the luminal $\mathrm{H}_{2} \mathrm{O}_{2}$-oxidized cysteines [41]. This is clearly visible in Fig. 5b showing the faster declining phase (i.e. higher pumping rate of SERCA) after depolarization in case of both selenium compounds. In the absence of SelN, excessive oxidation of SERCA results in reduced reuptake of calcium and an increase of cytosolic calcium at rest. This again results in a decrease in SR calcium content and associates with decreased muscle force.

It was also shown in zebrafish embryos that both SelN and RyR are required for normal muscle development. These two proteins are physically associated in vivo and SelN is necessary for full activation of RyR [42]. Our observation that Se supplementation increased the SelN level may also explain the increased intracellular calcium concentration change during depolarization. Combining its antioxidant effects on EC-coupling components with the latter the result could be an improved force production of skeletal muscle.

\section{The effects of selenium on muscle performance}

Several studies investigated the effects of selenium supplementation on body weights in chickens [43], lambs [44], 
cows [45], and also in laboratory animals like rats [46] and mice [13]. The results are diverse depending on the concentration, duration, and source of selenium. We found a slight but significant body weight and relative muscle weight increase in our experiments. This is in good agreement with a recent study in which fish oil and selenium supplementation was able to increase body and muscle weight in pathological conditions [47]. The authors gave a plausible explanation that the supplementation of selenium and fish oil improved the skeletal muscle atrophy due to down-regulation of myostatin and related cytokines. This pathway can work also in control condition and it is known that the inhibition of myostatin leads to extraordinary increase in muscle weight [20].

Even though selenium is widely used as dietary supplement alone or in combination with vitamins, its effects on muscle performance is under-investigated. Up to now only one clinical trial was conducted on humans [48]. In this study vitamin $E$, vitamin $C$, zinc, and selenium supplementation for 17 weeks improved maximal voluntary contraction, and endurance limit time of quadriceps by reducing oxidative stress and enhancing the antioxidant defenses. We found similar positive effects on force in EDL and SOL of mice just after 2 weeks application of selenium alone. Although, the whole muscle experiments were done on EDL and SOL, while isolated muscle fiber experiments were on FDB the results are reconcilable, since EDL and FDB contains essentially only fast-twitch fibers. The higher intracellular $\left[\mathrm{Ca}^{2+}\right]$ change during depolarization in FDB fibers from Se supplemented mice is well correlated with the higher force development in EDL from the same animal. The fact that the human study was conducted on Facioscapulohumeral muscular dystrophy patients, underline the potential application of selenium in medical treatment.

\section{Conclusion}

In conclusion, selenium has positive effects on the muscle performance of mice and NanoSe takes its effects already in low concentration. It increases the releasable calcium in the intracellular stores and the selenoprotein $\mathrm{N}$ expression in the muscles. Our results suggest that an antioxidant strategy with a low dose selenium supplementation could be a relevant therapeutic approach for patients with myopathies and could also serve as counteracting sarcopenia in the elderly.

\section{Additional file}

Additional file 1: Figure S1. Photo of bacterias (B) and elemental selenium nanoparticles (globular objects with 200-500 nm diameter) by scanning electron microscope. The elemental selenium nano-sized balls (NanoSe) have red color in truth. Figure S2 150 tetani were elicited at 0.5 $\mathrm{Hz}$ during $5 \mathrm{~min}$. The amplitude of tetani was normalized to the first tetanus. (PDF $280 \mathrm{~kb}$ )

\section{Abbreviations}

$\left[\mathrm{Ca}^{2+}\right]_{\mathrm{i}}$ : Intracellular calcium concentration; A/D: Analog to digital;

AM: Acetoxymethyl; ANOVA: Analysis of variance; BCA: Bicinchoninic acid;

BSA: Bovine serum albumin; $\mathrm{Ca}_{\text {total }}$ : The total $\mathrm{Ca}^{2+}$ in the myoplasm; $\mathrm{Ca}_{\text {transp: }}$ : The amount of $\mathrm{Ca}^{2+}$ transported by the $\mathrm{Ca}^{2+}$ pumps; DHPR: Dihydropyridine receptor; DNA: Deoxyribonucleic acid; DTT: Dithiothreitol; EC-coupling: Excitation contraction coupling; EDL: extensor digitorum longus muscle; EGTA: Ethylene glycol-bis ( $\beta$-aminoethyl ether)-N,N,N',N'-tetraacetic acid; $F_{340}, F_{380}$ : Fluorescence intensity at 340 or $380 \mathrm{~nm}$ illumination; FDB: flexor digitorum brevis muscle; FL: Flux; GPx: Glutathione peroxidase; GSH: Reduced glutathione; HRP: Horseradish peroxidase; Kd: Dissociation constant; MRS: Liquid culture medium for the isolation of lactobacilli, according to de Man, Rogosa and Sharpe; NanoSe: Nano-sized (100 to 500 nm diameter) elemental selenium; PBS: Phosphate-buffered saline; PBST: PBS supplemented with $0.1 \%$ Tween 20; ppm: Particle per million; RDA: Recommended daily allowance; RyR: Ryanodine receptor; SelN: Selenoprotein N; SEM: Standard error of the mean; SEPN1: Gene encodes selenoprotein N; SERCA: Sarcoplasmic reticulum calcium pump; SOL: musculus soleus; SR: Sarcoplasmic reticulum; T-tubule: Transverse tubule

\section{Acknowledgement}

The authors thank to Ms. R. Ori for her excellent technical assistance.

\section{Funding}

This work was supported by grant from the National Research, Development and Innovation Office (NKFIH K115461), from the Hungarian Ministry of Education (TÁMOP-4.2.2.A-11/1/KONV-2012-0025 and TÁMOP-4.1.2.E-15/1/Konv-2015-0001).

\section{Availability of data and materials}

The datasets used and/or analysed during the current study available from the corresponding author on reasonable request.

\section{Authors' contributions}

Conceived and designed the experiments: DB, IB, JP, LC, PS. Performed the experiments: DB, OR, TO, EU, PS. Analyzed the data: DB, OR, TO, BD, PS. Contributed reagents/materials/analysis tools: DB, TO, IB, BB, JP, LC, PS. Wrote the paper: DB, TO, BD, BB, LC, PS. All authors critically revised the article and approved the final version.

\section{Competing interests}

The authors declare that they have no competing interests.

Consent for publication

Not applicable.

\section{Ethics approval and consent to participate}

Not applicable.

\section{Author details}

${ }^{1}$ Department of Physiology, Faculty of Medicine, University of Debrecen, P.O. Box 400, H-4002 Debrecen, Hungary. ${ }^{2}$ Department of Pharmacology and Pharmacotherapy, Faculty of Medicine, University of Debrecen, Debrecen, Hungary. ${ }^{3}$ Institute of Animal Science, Biotechnology and Nature, Faculty of the Agricultural and Food Sciences and Environmental Management, University of Debrecen, Debrecen, Hungary.

Received: 4 July 2016 Accepted: 18 October 2016

Published online: 03 November 2016

References

1. Pansarasa O, Bertorelli L, Vecchiet J, Felzani G, Marzatico F. Age-dependent changes of antioxidant activities and markers of free radical damage in human skeletal muscle. Free Radic Biol Med. 1999;27:617-22.

2. Rederstorff M, Krol A, Lescure A. Understanding the importance of selenium and selenoproteins in muscle function. Cell Mol Life Sci. 2006;63:52-9.

3. Fulle S, Protasi F, Di Tano G, Pietrangelo T, Beltramin A, Boncompagni S, Vecchiet $L$, Fanò $G$. The contribution of reactive oxygen species to sarcopenia and muscle ageing. Exp Gerontol. 2004;39:17-24.

4. Rayman MP. Selenium and human health. Lancet. 2012;379(9822):1256-68.

5. Chariot $P$, Bignani $O$. Skeletal muscle disorders associated with selenium deficiency in humans. Muscle Nerve. 2003;27:662-8. 
6. Vays VB, Eldarov CM, Vangely IM, Kolosova NG, Bakeeva LE, Skulachev VP. Antioxidant SkQ1 delays sarcopenia-associated damage of mitochondrial ultrastructure. Aging. 2014;6(2):140-8.

7. Lofstedt J. White muscle disease of foals. Vet Clin North Am Equine Pract. 1997;13:169-85.

8. Ishihara H, Kanda F, Matsushita T, Chihara K, Itoh K. White muscle disease in humans: myopathy caused by selenium deficiency in anorexia nervosa under long term total parenteral nutrition. J Neurol Neurosurg Psychiatry. 1999;67:829-30.

9. Food and health in Europe: a new basis of action. http://www.euro.who. int/_data/assets/pdf_file/0005/74417/E82161.pdf?ua=1

10. Stoffaneller R, Morse NL. A review of dietary selenium intake and selenium status in Europe and the Middle East. Nutrients. 2015;7:1494-537.

11. Ramya S, Shanmugasundaram T, Balagurunathan R. Biomedical potential of actinobacterially synthesized selenium nanoparticles with special reference to anti-biofilm, anti-oxidant, wound healing, cytotoxic and anti-viral activities. J Trace Elem Med Biol. 2015:32:30-9.

12. Eszenyi P, Sztrik A, Babka B, Prokisch J. Elemental, nano-sized (100-500 nm) selenium production by probiotic lactic acid bacteria. Int J Biosci Biochem Bioinformatics. 2011;1:148-52.

13. Benko I, Nagy G, Tanczos B, Ungvari E, Sztrik A, Eszenyi P, Prokisch J, Banfalv $\mathrm{G}$. Subacute toxicity of nano-selenium compared to other selenium species in mice. Environ Toxicol Chem. 2012;31(12):2812-20.

14. Ungvari E, Monori I, Megyeri A, Csiki Z, Prokisch J, Sztrik A, Jávor A, Benko I. Protective effects of meat from lambs on selenium nanoparticle supplemented diet in a mouse model of polycyclic aromatic hydrocarboninduced immunotoxicity. Food Chem Toxicol. 2014;64:298-306.

15. Petit N, Lescure A, Rederstorff M, Krol A, Moghadaszadeh B, Wewer UM, Guicheney P. Selenoprotein N: an endoplasmic reticulum glycoprotein with an early developmental expression pattern. Hum Mol Genet. 2003;12(9):1045-53.

16. Arbogast S, Ferreiro A. Selenoproteins and protection against oxidative stress: selenoprotein $\mathrm{N}$ as a novel player at the crossroads of redox signaling and calcium homeostasis. Antioxid Redox Signal. 2010;12(7):893-904

17. Franzini-Armstrong C. Architecture and regulation of the $\mathrm{Ca}^{2+}$ delivery system in muscle cells. Appl Physiol Nutr Metab. 2009;34(3):323-7.

18. Meissner G, Lu X. Dihydropyridine receptor-ryanodine receptor interactions in skeletal muscle excitation-contraction coupling. Biosci Rep. 1995;15(5):399-408.

19. Purina mouse diet 5015. http://www.labdiet.com/cs/groups/lolweb/ @labdiet/documents/web_content/mdrf/mdi4/ edisp/ducm04_028439.pdf

20. Bodnar D, Geyer N, Ruzsnavszky O, Olah T, Hegyi B, Sztretye M, Fodor J, Dienes B, Balogh A, Papp Z, Szabo L, Muller G, Csernoch L, Szentesi P. Hypermuscular mice with mutation in the myostatin gene display altered calcium signaling. J Physiol. 2014;592:1353-65.

21. Oddoux S, Brocard J, Schweitzer A, Szentesi P, Giannesini B, Brocard J, Fauré J, Pernet-Gallay K, Bendahan D, Lunardi J, Csernoch L, Marty I. Triadin deletion induces impaired skeletal muscle function. J Biol Chem. 2009;284:34918-29.

22. Fodor J, Gonczi M, Sztretye M, Dienes B, Olah T, Szabo L, Csoma E, Szentesi P, Szigeti GP, Marty I, Csernoch L. Altered expression of triadin 95 causes parallel changes in localized $\mathrm{Ca}^{2+}$ release events and global $\mathrm{Ca}^{2+}$ signals in skeletal muscle cells in culture. J Physiol. 2008;586:5803-18.

23. Szentesi $P$, Jacquemond V, Kovács L, Csernoch L. Intramembrane charge movement and sarcoplasmic calcium release in enzymatically isolated mammalian skeletal muscle fibres. J Physiol. 1997:505:371-84.

24. Tóth A, Fodor J, Vincze J, Oláh T, Juhász T, Zákány R, Csernoch L, Zádor E. The effect of SERCA1b silencing on the differentiation and calcium homeostasis of C2C12 skeletal muscle cells. PLoS One. 2015;10(4):e0123583.

25. Escobar AL, Velez P, Kim AM, Cifuentes F, Fill M, Vergara JL. Kinetic properties of DM-nitrophen and calcium indicators: rapid transient response to flash photolysis. Pflugers Arch. 1997;434(5):615-31.

26. Lefebvre R, Legrand C, González-Rodríguez E, Groom L, Dirksen RT, Jacquemond $V$. Defects in $\mathrm{Ca}^{2+}$ release associated with local expression of pathological ryanodine receptors in mouse muscle fibres. J Physiol. 2011; 589(22):5361-82.

27. Szappanos H, Cseri J, Deli T, Kovács L, Csernoch L. Determination of depolarisation- and agonist-evoked calcium fluxes on skeletal muscle cells in primary culture. J Biochem Biophys Methods. 2004;59(1):89-101.

28. Andrade FH, Anzueto A, Napier W, Levine S, Lawrence RA, Jenkinson SG, Maxwell LC. Effects of selenium deficiency on diaphragmatic function after resistive loading. Acta Physiol Scand. 1998;162(2):141-8.

29. Juszczuk-Kubiak E, Bujko K, Cymer M, Wicińska K, Gabryszuk M, Pierzchała M. Effect of inorganic dietary selenium supplementation on selenoprotein and lipid metabolism gene expression patterns in liver and loin muscle of growing lambs. Biol Trace Elem Res. 2016:172(2):336-45.

30. Metes-Kosik N, Luptak I, Dibello PM, Handy DE, Tang SS, Zhi H, Qin F, Jacobsen DW, Loscalzo J, Joseph J. Both selenium deficiency and modest selenium supplementation lead to myocardial fibrosis in mice via effects on redox-methylation balance. Mol Nutr Food Res. 2012;56(12):1812-24.

31. Moghadaszadeh B, Rider BE, Lawlor MW, Childers MK, Grange RW, Gupta K, Boukedes SS, Owen CA, Beggs AH. Selenoprotein N deficiency in mice is associated with abnormal lung development. FASEB J. 2013;27(4):1585-99.

32. Turan B, Hotomaroglu O, Kiliç M, Demirel-Yilmaz E. Cardiac dysfunction induced by low and high diet antioxidant levels comparing selenium and vitamin E in rats. Regul Toxicol Pharmacol. 1999;29(2 Pt 1):142-50.

33. Raines AM, Sunde RA. Selenium toxicity but not deficient or supernutritiona selenium status vastly alters the transcriptome in rodents. BMC Genomics. 2011:12:26.

34. Forootanfar $H$, Adeli-Sardou M, Nikkhoo M, Mehrabani M, Amir-Heidari B, Shahverdi AR, Shakibaie M. Antioxidant and cytotoxic effect of biologically synthesized selenium nanoparticles in comparison to selenium dioxide. J Trace Elem Med Biol. 2014;28:75-9.

35. Anzueto A, Supinski GS, Levine SM, Jenkinson SG. Mechanisms of disease: are oxygen-derived free radicals involved in diaphragmatic dysfunction? Am J Respir Crit Care Med. 1994;149(4 Pt 1):1048-52.

36. Hartell MG, Borzone G, Clanton TL, Berliner LJ. Detection of free radicals in blood by electron spin resonance in a model of respiratory failure in the rat. Free Radic Biol Med. 1994;17(5):467-72.

37. Reid MB, Haack KE, Franchek KM, Valberg PA, Kobzik L, West MS. Reactive oxygen in skeletal muscle. I. Intracellular oxidant kinetics and fatigue in vitro. J Appl Physiol. 1992;73(5):1797-804.

38. Shindoh C, DiMarco A, Thomas A, Manubay P, Supinski G. Effect of Nacetylcysteine on diaphragm fatigue. J Appl Physiol. 1990;68(5):2107-13.

39. Aracena P, Tang W, Hamilton SL, Hidalgo C. Effects of S-glutathionylation and S-nitrosylation on calmodulin binding to triads and FKBP12 binding to type 1 calcium release channels. Antioxid Redox Signal. 2005;7(7-8):870-81.

40. Okatan EN, Tuncay E, Turan B. Cardioprotective effect of selenium via modulation of cardiac ryanodine receptor calcium release channels in diabetic rat cardiomyocytes through thioredoxin system. J Nutr Biochem. 2013:24(12):2110-8.

41. Marino M, Stoilova T, Giorgi C, Bachi A, Cattaneo A, Auricchio A, Pinton P, Zito E. SEPN1, an endoplasmic reticulum-localized selenoprotein linked to skeletal muscle pathology, counteracts hyperoxidation by means of redoxregulating SERCA2 pump activity. Hum Mol Genet. 2015;24:1843-55.

42. Jurynec MJ, Xia R, Mackrill JJ, Gunther D, Crawford T, Flanigan KM, Abramson JJ, Howard MT, Grunwald DJ. Selenoprotein N is required for ryanodine receptor calcium release channel activity in human and zebrafish muscle. PNAS. 2008;105(34):12485-90.

43. Habibian M, Ghazi S, Moeini MM. Effects of dietary selenium and vitamin $\mathrm{E}$ on growth performance, meat yield, and selenium content and lipid oxidation of breast meat of broilers reared under heat stress. Biol Trace Elem Res. 2016;169(1):142-52.

44. Sushma K, Reddy YR, Kumari NN, Reddy PB, Raghunandan T, Sridhar K. Effect of selenium supplementation on performance, cost economics, and biochemical profile of Nellore ram lambs. Vet World. 2015;8(9):1150-5.

45. Liao SF, Brown KR, Stromberg AJ, Burris WR, Boling JA, Matthews JC. Dietary supplementation of selenium in inorganic and organic forms differentially and commonly alters blood and liver selenium concentrations and liver gene expression profiles of growing beef heifers. Biol Trace Elem Res. 2011;140(2):151-69.

46. Erkhembayar S, Mollbrink A, Eriksson M, Larsen EH, Eriksson LC. Selenium homeostasis and induction of thioredoxin reductase during long term selenite supplementation in the rat. J Trace Elem Med Biol. 2011;25(4):254-9.

47. Wang H, Li TL, Hsia S, Su IL, Chan YL, Wu CJ. Skeletal muscle atrophy is attenuated in tumor-bearing mice under chemotherapy by treatment with fish oil and selenium. Oncotarget. 2015;6(10):7758-73.

48. Passerieux E, Hayot M, Jaussent A, Carnac G, Gouzi F, Pillard F, Picot MC, Böcker K, Hugon G, Pincemail J, Defraigne JO, Verrips T, Mercier J, LaoudjChenivesse D. Effects of vitamin C, vitamin E, zinc gluconate, and selenomethionine supplementation on muscle function and oxidative stress biomarkers in patients with facioscapulohumeral dystrophy: a double-blind randomized controlled clinical trial. Free Radic Biol Med. 2015;81:158-69. 